Check for updates

Cite this: RSC Adv., 2018, 8, 4230

Received 15th December 2017

Accepted 17th January 2018

DOI: $10.1039 / c 7 r a 13369 c$

rsc.li/rsc-advances

\section{Kinetic and mechanistic study on gas phase reactions of ozone with a series of cis-3-hexenyl esters $\uparrow$}

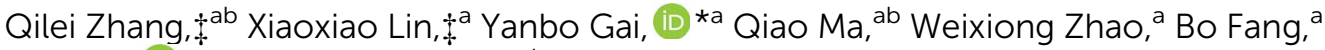 \\ Bo Long $\left({ }^{c}{ }^{c}\right.$ and Weijun Zhang ${ }^{\star a d}$
}

As an important group of green leaf volatiles (GLVs), C6 hexenyl esters, are found to be widely emitted into the atmosphere by plants and vegetation, especially when they suffer mechanical damage. It is indispensable to understand their atmospheric fate for environmental assessment and model simulation. In this paper, the rate constants for reactions of $\mathrm{O}_{3}$ with four cis-3-hexenyl esters have been measured using an absolute method in a flow tube reactor at $298 \mathrm{~K}$ and atmospheric pressure. The measured rate constants (in $10^{-17}$ $\mathrm{cm}^{3}$ per molecule per s) were $4.06 \pm 0.66$ for cis-3-hexenyl formate, $5.77 \pm 0.70$ for cis-3-hexenyl acetate, $7.62 \pm 0.88$ for cis-3-hexenyl propionate, and $12.34 \pm 1.59$ for cis-3-hexenyl butyrate, respectively. Theoretical calculations were also carried out for the title reactions to better understand their kinetics and mechanism using density functional theory (DFT) and transition state theory (TST). Geometry optimizations, energy and harmonic vibrational frequency calculations were performed for all of the stationary points at the BHandHLYP/6-311+G(d,p) level of theory. The calculated rate constants were in good agreement with the experimental values. The results showed that the reactivity of the studied compounds towards $\mathrm{O}_{3}$ was obviously dependent on their chemical structure, such as the nature of the substituent, and the relative positions of the double bond and the substituent. The results were also discussed in terms of their atmospheric importance in the degradation of these unsaturated esters by comparing their lifetimes with respect to their reactions with $\mathrm{O}_{3}$ and other main atmospheric oxidants.

\section{Introduction}

Large quantities of volatile organic compounds (VOCs) are emitted directly into the atmosphere from biogenic and anthropogenic sources, of which biogenic volatile organic compounds (BVOCs) account for about $90 \%$ estimated on a global basis., ${ }^{1,2}$ Because of their relatively high atmospheric reactivity, BVOCs are believed to play a central role in determining atmospheric composition and the oxidizing capacity of the atmosphere. ${ }^{3-5}$ Many studies have found great discrepancy between measured and simulated $\mathrm{OH}$ concentration, total $\mathrm{OH}$ reactivity and also the production of ozone.$^{6-8}$ In addition to the uncertainty in the understanding of VOC emissions, the lack of

\footnotetext{
${ }^{a}$ Laboratory of Atmospheric Physico-Chemistry, Anhui Institute of Optics and Fine Mechanics, Chinese Academy of Sciences, Hefei, 230031, Anhui, China. E-mail: gaiyanbo@aiofm.ac.cn

${ }^{b}$ University of Science and Technology of China, Hefei 230026, China

${ }^{c}$ School of Materials Science and Engineering, Guizhou Minzu University, Guiyang 550025, China

${ }^{d}$ School of Environmental Science and Optoelectronic Technology, University of Science and Technology of China, Hefei, 230026, Anhui, China

$\dagger$ Electronic supplementary information (ESI) available. See DOI: 10.1039/c7ra13369c

\$ These authors contributed equally to this work.
}

systematic understanding of the reaction process of identified VOCs is also an important reason for this discrepancy. Thus, it is very important to thoroughly study the reaction processes, including atmospheric degradation mechanisms, and kinetic information, for all the VOCs emitted into the atmosphere.

Green leaf volatiles (GLVs) are one of the most important groups of BVOCs, represented by a series of C5 and C6 oxygenated hydrocarbons. They are produced within plant cells through biochemical conversion of some fatty acid, and emitted into the atmosphere by vegetation during the developmental processes or in response to external stress. ${ }^{9,10}$ As an important class of components, C6 hexenyl esters have been extensively detected. For example, many studies have shown that cis-3-hexenyl acetate is one of the major components of vegetation emissions, ${ }^{\mathbf{1 1 - 1 4}}$ and sometimes accounts for more than $40 \%$ of the total emissions. ${ }^{15,16}$ It has also been demonstrated as the predominant wound-inducible volatile signal that mediates indirect defense responses by directing tritrophic (plant-herbivore-natural enemy) interactions. ${ }^{17}$ Besides cis-3-hexenyl acetate, other C6 hexenyl esters have also been recognized to contribute a significant fraction to the total BVOC flux, such as cis-3-hexenyl formate, cis-3-hexenyl butyrate and cis-3-hexenyl isovalerate. ${ }^{\mathbf{1 8 - 2 0}}$

Although reaction with $\mathrm{OH}$ may be the dominant degradation pathway for these esters in the atmosphere, reaction with 
$\mathrm{O}_{3}$ may also play an important role, especially in polluted areas. ${ }^{4}$ Because of the higher concentration of $\mathrm{O}_{3}$ than that of $\mathrm{OH}$, when rate constants for reactions of these unsaturated esters with ozone reach $10^{-17} \mathrm{~cm}^{3}$ per molecule per s, oxidation of these esters by $\mathrm{O}_{3}$ would be competitive with $\mathrm{OH}$ reactions. In the literature, reaction of cis-3-hexenyl acetate with $\mathrm{O}_{3}$ has been studied by two groups and the rate constants reported were at $(5.4 \pm 1.4) \times 10^{-17} \mathrm{~cm}^{3}$ per molecule per $\mathrm{s}$ and $(5.9 \pm 0.87) \times$ $10^{-17} \mathrm{~cm}^{3}$ per molecule per s, respectively, which indicates that reaction with $\mathrm{O}_{3}$ cannot be ignored for the atmospheric degradation of cis-3-hexenyl acetate..$^{\mathbf{2 1 , 2 2}}$

In this work, we have studied the reaction kinetics of $\mathrm{O}_{3}$ with four cis-3-hexenyl esters (cis-3-hexenyl formate, cis-3-hexenyl acetate, cis-3-hexenyl propionate and cis-3-hexenyl butyrate) and isoprene using experimental methods in a flow tube reactor as well as using theoretical methods. As far as we know, there are still no kinetic data for the $\mathrm{O}_{3}$ reactions with cis-3-hexenyl formate, cis-3-hexenyl propionate and cis-3-hexenyl butyrate in the literature. Thus, this work provides the first kinetic study for these reactions. The results can help to evaluate the lifetime, main removal pathways and influence area of these esters in the atmosphere and can also be used as input data of atmospheric chemical models for more accurate air quality predictions.

\section{Experimental and theoretical methods}

\section{Experimental}

Experiments were carried out in a coaxial double-tube flow reactor. The outer tube (i.d. $36 \mathrm{~mm}$, length $100 \mathrm{~cm}$ ) was for the VOC flow. The inner (i.d. $4 \mathrm{~mm}$, length $120 \mathrm{~cm}$ ) was for the $\mathrm{O}_{3}$ flow, which was movable along a range of axial positions. The end of the inner tube was designed with a series of small emitting holes to allow the reagent flows from the inner and the outer tubes better mixed. The schematic diagram of the experimental setup and gas flow is shown in Fig. S1 in the (ESI $\dagger$ ).

Clean zero air was used as bath gas, which was generated from a zero air generator (AADCO, 737-15). $\mathrm{O}_{3}$ was generated via electrical discharge by an ozone generator (COM-AD-01, ANSEROS, Germany). A known amount of the liquid VOC reagent was injected into a heated three-necked flask with microsyringe and flushed into a Teflon bag by zero air to obtain certain concentration of VOCs. A sampling pump (GM-1.0A, Jinteng Experimental Equipment Co., Ltd.) operated at the central outlet of the reactor draws forward the gas flow through the reactor. The $\mathrm{O}_{3}$ flow and VOC flow were set at about 0.5 $\mathrm{L} \mathrm{min}^{-1}$ and $1.6 \mathrm{~L} \mathrm{~min}^{-1}$, respectively, by mass flow controllers (MFC, D08-8C, Beijing Sevenstar Electronics). Thus, the initial concentration of the VOC in the flow reactor could be calculated from its original concentration in the Teflon bag and the flow rates of both the $\mathrm{O}_{3}$ and VOC flow in the reactor. An ozone analyzer (Model 49i, Thermo Scientific) was used to measure the concentration of $\mathrm{O}_{3}$ at the end of the reactor tube. The reaction time was varied in the range of $0-25 \mathrm{~s}$ by adjusting the position of the inner tube relatively to the sampling point $(0-80 \mathrm{~cm})$. In our experimental conditions, the Reynolds number calculated was $\sim 90$ with the linear flow velocity at $\sim 3.44 \mathrm{~cm} \mathrm{~s}^{-1}$, corresponding to a laminar flow. Experiments were conducted at a total pressure of 760 Torr and room temperature (298 $\pm 2 \mathrm{~K})$ with the relative humidity $\leq 5 \%$.

The rate constants were measured under pseudo-first-order conditions with the range of $[\mathrm{VOC}]_{0} /\left[\mathrm{O}_{3}\right]_{0}$ at about $100-500$, which had been used in our previous works. ${ }^{23,24}$ The temporal profile of $\left[\mathrm{O}_{3}\right]$ can be given as:

$$
\left[\mathrm{O}_{3}\right]_{t}=\left[\mathrm{O}_{3}\right]_{0} \exp \left(-k^{\prime} t\right)
$$

then

$$
\ln \frac{\left[\mathrm{O}_{3}\right]_{0}}{\left[\mathrm{O}_{3}\right]_{t}}=k^{\prime} t
$$

where

$$
k^{\prime}=k_{i}[\mathrm{VOC}]_{0}+k_{\mathrm{W}}
$$

where $k^{\prime}$ represents the pseudo-first-order rate constant, $k_{\mathrm{W}}$ is the $\mathrm{O}_{3}$ decay rate in the absence of VOC. $k_{i}$ is the rate constant for the reaction of $\mathrm{O}_{3}$ with the studied VOC to be measured. Thus, with the $\mathrm{O}_{3}$ concentration measured during the reaction, $k^{\prime}$ can be obtained from eqn (II). Then $k_{i}$ can be derived by eqn (III) from the obtained values of $k^{\prime}$ at various [VOC] $]_{0}$.

The VOC reagents involved in this work included isoprene and a series of cis-3-hexenyl esters. The sources and their stated purity levels were as follows: cis-3-hexenyl formate (97\%), cis-3hexenyl acetate (98\%), cis-3-hexenyl propionate (98\%), cis-3hexenyl butyrate (98\%), Adamas Reagent Co., Ltd.; isoprene (99\%), Alfa Asaer Co., Ltd. Cyclohexane ( $\geq 99.5 \%)$ was also used in some experiments as $\mathrm{OH}$ radical scavenger, which was from Sinopharm chemical reagent Co., Ltd.

\section{Theoretical calculations}

The reactions of cis-3-hexenyl formate, cis-3-hexenyl acetate, cis-3hexenyl propionate and cis-3-hexenyl butyrate with $\mathrm{O}_{3}$ have been described at the density functional theory (DFT) level, employing the BHandHLYP functional and the $6-311+G(d, p)$ basis sets. Geometry optimizations, energies and the harmonic vibrational frequencies calculations were performed for all of the stationary points at the BHandHLYP/6-311+G(d,p) level of theory. Each local minimum has all positive frequencies and each transition state (TS) has one imaginary frequency. In addition, the connection between each minimum and the corresponding transition state (TS) was confirmed with intrinsic reaction path (IRC) method calculations. ${ }^{25}$ Quantum chemical calculations were performed with the Gaussian 09 program. ${ }^{26}$ The reaction rate constants were calculated using multiconformer transition state theory (MCTST) as the reactions involve multiple conformers. ${ }^{27}$ For example, it includes two conformers (cis and trans) of the reactant and eight conformers of the transition state (TS1-TS8) in the reaction of cis-3-hexenyl formate with $\mathrm{O}_{3}$.

\section{Results and discussion}

\section{Absolute rate constant measurements}

The initial concentrations used in the reactions were $(0.74-2.58)$ $\times 10^{12}$ molecule per $\mathrm{cm}^{3}$ for $\mathrm{O}_{3}$ and (1.51-6.51) $\times 10^{14}$ molecule 
per $\mathrm{cm}^{3}$ for cis-3-hexenyl esters. In the absence of $\mathrm{O}_{3}$, the wall loss of the cis-3-hexenyl esters in the flow tube was first measured using a gas chromatography-flame ionization detector (GC-FID, 7820A, Agilent Technologies), which was showed to be negligible. Moreover, the GC-measured concentration of the studied esters in the reactor was very consistent with the concentration calculated based on its original concentration in the Teflon bag and the flow rates in the reactor. Thus, the calculated initial concentrations were used in the following experiments. It is well known that $\mathrm{OH}$ radicals could be produced in the ozone reactions with unsaturated VOCs ${ }^{28-30}$ which would cause possible change in the VOC concentration. Thus, comparative experiments with and without cyclohexane as $\mathrm{OH}$ scavenger were conducted, and no significant difference was found in the rate constants. Fig. $\mathrm{S} 2 \dagger$ gives one example of comparative experiments in the reaction of $\mathrm{O}_{3}$ with cis-3-hexenyl acetate. Actually, since the initial concentration of the esters was in large excess than $\mathrm{O}_{3}$, it would almost not change during the reaction. So that loss of the esters caused by reaction with $\mathrm{OH}$ radicals would have a negligible effect on the experiments.

To validate the setup and the methods, rate constant for the reaction of $\mathrm{O}_{3}$ with isoprene was at first measured, which has been widely studied in the literatures. ${ }^{31,32}$ The initial concentrations of isoprene used were in the range of $(5.25-10.5) \times 10^{14}$ molecule per $\mathrm{cm}^{3}$. In all experiments, the ozone concentration with the inner tube at different positions was measured, corresponding to the ozone concentration at different reaction time. Experiments at each initial concentrations of isoprene were repeated at least twice. One typical set of pseudo-first-order plots for $\mathrm{O}_{3}$ reactions with different concentrations of isoprene is shown in Fig. S3. $\uparrow$ The slope of each straight line gives the pseudo-first-order rate constants, $k^{\prime}$. The absolute rate constant, $k_{i}$, then was obtained by plotting all the data sets of $k^{\prime}$ against their corresponding [isoprene $]_{0}$ in Fig. 1 . The determined rate constant was $(1.23 \pm 0.16) \times 10^{-17} \mathrm{~cm}^{3}$ per molecule per $\mathrm{s}$. It was in very good agreement with the IUPAC recommended value for $k_{\mathrm{O}_{3}+\text { isoprene }}$ which was $1.27 \times 10^{-17} \mathrm{~cm}^{3}$ per molecule per $\mathrm{s.}^{32}$

Then, reactions of $\mathrm{O}_{3}$ with four cis-3-hexenyl esters, cis-3hexenyl formate, cis-3-hexenyl acetate, cis-3-hexenyl propionate and cis-3-hexenyl butyrate, were studied. Fig. 2 shows one group of the typical pseudo-first-order plots for $\mathrm{O}_{3}$ reactions with different concentrations of cis-3-hexenyl acetate. Pseudo-first-order plots for other esters studied are given in Fig. S4-S6 in ESI. $\dagger$ In the flow reactor, the pseudo-first-order rate constants obtained may be subject to diffusion processes. ${ }^{33-35}$ So corrections were made to the experimentally obtained $k^{\prime}$ values considering the axial and radial diffusion of $\mathrm{O}_{3}$ by:

$$
k_{\text {corrected }}^{\prime}=k_{\exp }^{\prime}\left(1+\frac{k_{\exp }^{\prime} D}{\nu^{2}}+\frac{k_{\exp }^{\prime} r^{2}}{48 D}\right)
$$

where $k_{\exp }^{\prime}$ is the experimentally obtained pseudo-first-order rate constants $\left(\mathrm{s}^{-1}\right), r$ is the reactor radius $(\mathrm{cm}), \nu$ is the average linear velocity $\left(\mathrm{cm} \mathrm{s}^{-1}\right), D$ is the molecular diffusion coefficient of $\mathrm{O}_{3}$ in air which was estimated to be $0.169 \mathrm{~cm}^{2} \mathrm{~s}^{-1}$

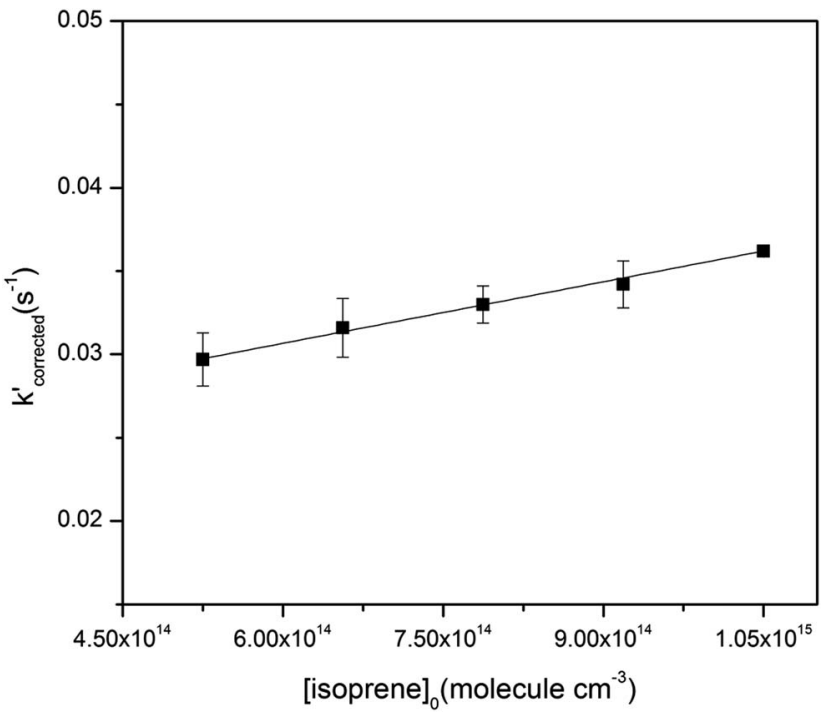

Fig. 1 Plot of $k^{\prime}$ (corrected) versus initial isoprene concentrations.

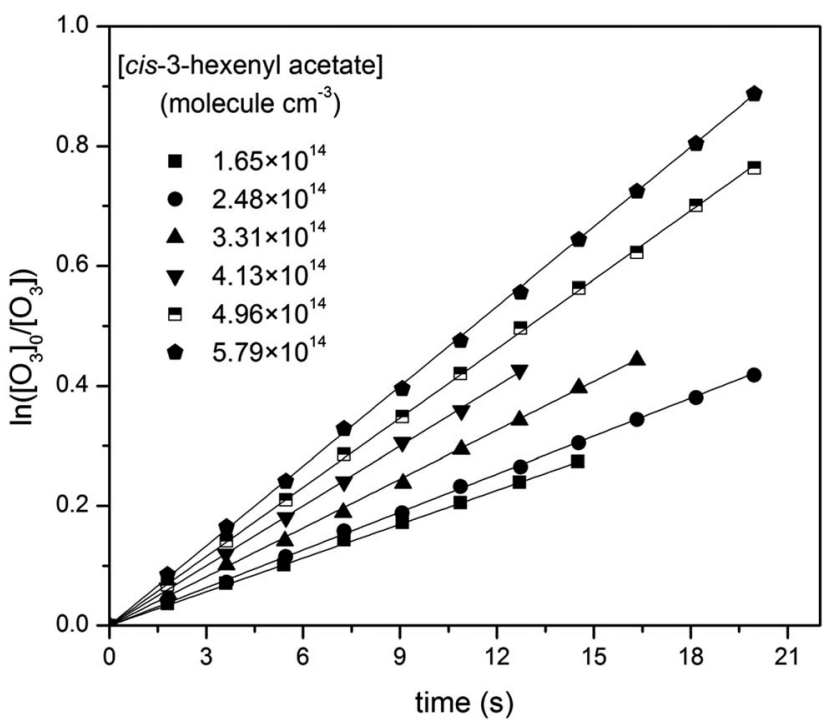

Fig. 2 Pseudo-first-order plots for $\mathrm{O}_{3}$ reactions with different concentrations of cis-3-hexenyl acetate (in molecule per $\mathrm{cm}^{3}$ ).

at $298 \mathrm{~K}$ and 760 torr. ${ }^{36}$ The final correction factor for $k_{\text {exp }}^{\prime}$ was in the range of 1.01-1.03, which indicated that the influence of diffusion could be negligible in this work. To be accurate, $k^{\prime}$ corrected were still used.

Plotting $k_{\text {corrected }}^{\prime}$ against the initial ester concentrations yields the second order rate constant. Plots for four studied esters are shown in Fig. 3, all of which showed good linearity. As a result, the acquired rate constants for the studied reactions are as follows, with the errors including $2 \sigma$ from the least-square fitting and a systematic error estimated $\sim 10 \%$ which was believed to include errors from the measurement of $\left[\mathrm{O}_{3}\right]$, the initial concentration calculation of the esters, the flow measurement in the reactor, and some other possible errors. 


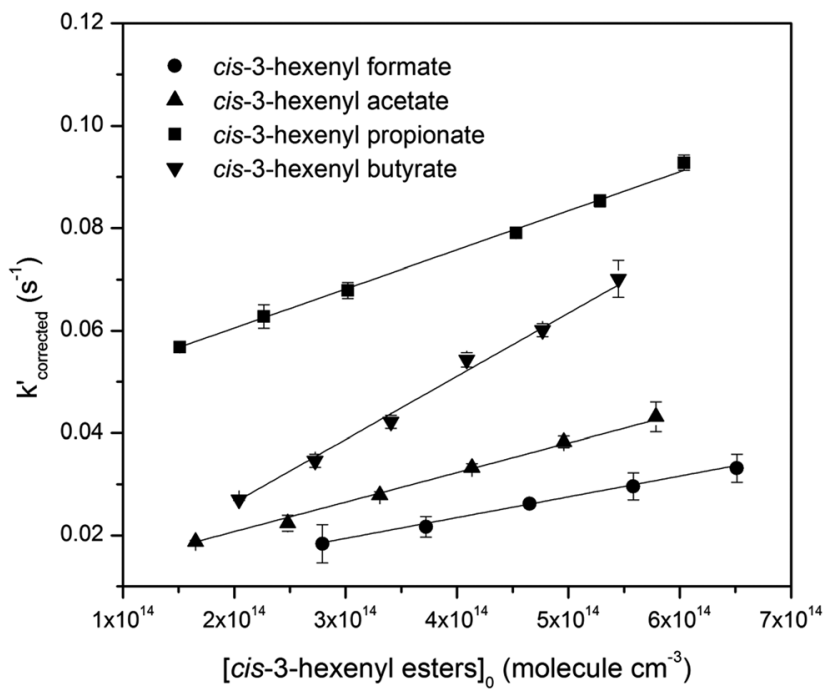

Fig. 3 Plots of $k^{\prime}$ (corrected) versus initial ester concentrations at room temperature. The lines represent linear least-squares fitting (in order to express more clearly, the plots of cis-3-hexenyl propionate was artificially shifted upward by 0.04 )

$k_{\text {cis-3-hexenyl formate }}=(4.06 \pm 0.66) \times 10^{-17} \mathrm{~cm}^{3}$ per molecule per s $k_{\text {cis-3-hexenyl acetate }}=(5.77 \pm 0.70) \times 10^{-17} \mathrm{~cm}^{3}$ per molecule per s $k_{c i s-3-\text { hexenyl propionate }}=(7.62 \pm 0.88) \times 10^{-17} \mathrm{~cm}^{3}$ per molecule per s $k_{\text {cis-3-hexenyl butyrate }}=(12.34 \pm 1.59) \times 10^{-17} \mathrm{~cm}^{3}$ per molecule per s

Of the four cis-3-hexenyl esters studied here, only reaction of cis-3-hexenyl acetate has been studied previously. Using cis-2butene as reference compound, Atkinson $e t$ al. gave a relative rate constant of $(5.4 \pm 1.4) \times 10^{-17} \mathrm{~cm}^{3}$ per molecule per s. ${ }^{21}$ Then Grosjean et al. reported an absolute rate constant for this reaction, which was $(5.9 \pm 0.87) \times 10^{-17} \mathrm{~cm}^{3}$ per molecule per s. ${ }^{22}$ The value we measured in this work at $(5.77 \pm 0.70) \times$ $10^{-17} \mathrm{~cm}^{3}$ per molecule per s agreed very well with both of these literature data within the stated uncertainties. For reactions of $\mathrm{O}_{3}$ with other three esters, to the best of our knowledge, no previously reported kinetic values are available, and thus, no direct comparisons with literature are made here.

\section{Reaction mechanism and theoretical rate constants}

The $\mathrm{O}_{3}$ reactions with unsaturated compounds are initiated by the 1,3-dipolar addition of $\mathrm{O}_{3}$ to the $\mathrm{C}=\mathrm{C}$ bond through a transition state (TS), which leads to the production of a primary ozonide (POZ). ${ }^{24,37,38}$ Scheme 1 illustrates the mechanism of cis-3-hexenyl formate with $\mathrm{O}_{3}$. Structures of the reactants, the transition states (TS) and the primary ozonide for the reaction of $\mathrm{O}_{3}$ with cis-3-hexenyl formate are given in Fig. 4, and those for other esters are given in Fig. S7-S9. $\dagger$ There are two conformers (cis and trans) of the reactant for the cis-3-hexenyl formate, cis-3-hexenyl acetate, cis-3-hexenyl propionate and cis-3-hexenyl butyrate, respectively. Eight transition states,

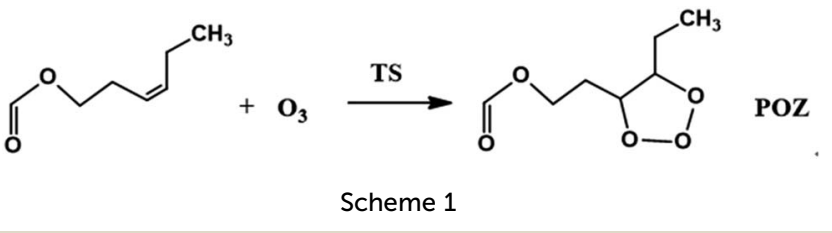

TS1-TS8, were identified associated with the production of the primary ozonides (POZ1-POZ8) from each unsaturated ester ozonolysis reactions. The potential energy surface for the reaction pathways are presented in Fig. 5 and $\mathrm{S} 10-\mathrm{S} 12 \dagger$ at the BH\&HLYP/6-311+G(d,p) level of theory. All of the ozone addition reactions are highly exothermic, with the reaction energies more than $270 \mathrm{~kJ} \mathrm{~mol}^{-1}$.

Rate constants including tunneling at $298 \mathrm{~K}$ for each unsaturated ester were calculated. There are several methods for tunneling corrections. ${ }^{39-41}$ In this work, Eckart tunneling ${ }^{42}$ was used, which has been performed on the TheRate program. ${ }^{43}$ The rate constant is expressed as

$$
k=\sigma \kappa \frac{k_{\mathrm{B}} T}{h} \frac{Q_{\mathrm{TS}}^{\ddagger}}{Q_{\mathrm{R} 1} Q_{\mathrm{R} 2}} \mathrm{e}^{-\Delta E^{\ddagger} / R T}
$$

where $\sigma$ is the symmetry factor, $\kappa$ is the tunneling factor (Eckart tunneling correction), $k_{\mathrm{B}}$ and $h$ are the Boltzmann and Planck constants, respectively, $Q_{\mathrm{TS}}^{ \pm}$is the partition function of the transition state, $Q_{\mathrm{R} 1}$ and $Q_{\mathrm{R} 2}$ are the partition functions of the reactants (R), and $\Delta E^{*}$ is the barrier height of the reaction. This method has been extensively utilized in the atmospheric reactions. ${ }^{44-47}$

The calculated rate constants for the reactions of ozone with each unsaturated ester are $6.60 \times 10^{-17} \mathrm{~cm}^{3}$ per molecule per s, $6.84 \times 10^{-17} \mathrm{~cm}^{3}$ per molecule per s, $10.84 \times 10^{-17} \mathrm{~cm}^{3}$ per molecule per s, and $17.89 \times 10^{-17} \mathrm{~cm}^{3}$ per molecule per $\mathrm{s}$, respectively.

\section{Reactivity trends}

As mentioned above, the reaction of ozone with unsaturated VOCs begins with the electrophilic addition of ozone to the carbon-carbon double bond. Thus, the factors that affect the electronic density on the double bond will also affect the reactivity of unsaturated VOCs toward ozone. Table 1 shows the rate constants for the reactions studied in this work and those for reactions of several compounds with similar structures in the literature.

It can be seen that, the rate constants for the four studied cis3-hexenyl esters are all smaller than that of cis-3-hexene, reflecting the electron-withdrawing effect of the -OC $(\mathrm{O}) \mathrm{R}$ function group. And the rate constants toward $\mathrm{O}_{3}$ increase with the length of $\mathrm{R}$ group ( $\mathrm{R}$ from $\mathrm{H}, \mathrm{CH}_{3}, \mathrm{CH}_{2} \mathrm{CH}_{3}$ to $\mathrm{CH}_{2} \mathrm{CH}_{2} \mathrm{CH}_{3}$ ). The theoretical calculation results show similar reactivity trend, i.e., the reaction rate increases from cis-3-hexenyl formate to cis3-hexenyl butyrate. When the ester group is separated from the $\mathrm{C}=\mathrm{C}$ double bond by $\mathrm{CH}_{2}$ group, comparing vinyl acetate with cis-3-hexenyl acetate, and vinyl propionate with cis-3-hexenyl propionate in Table 1, the electron-withdrawing influence of the ester group on the reactivity reduced, and the rate constants 

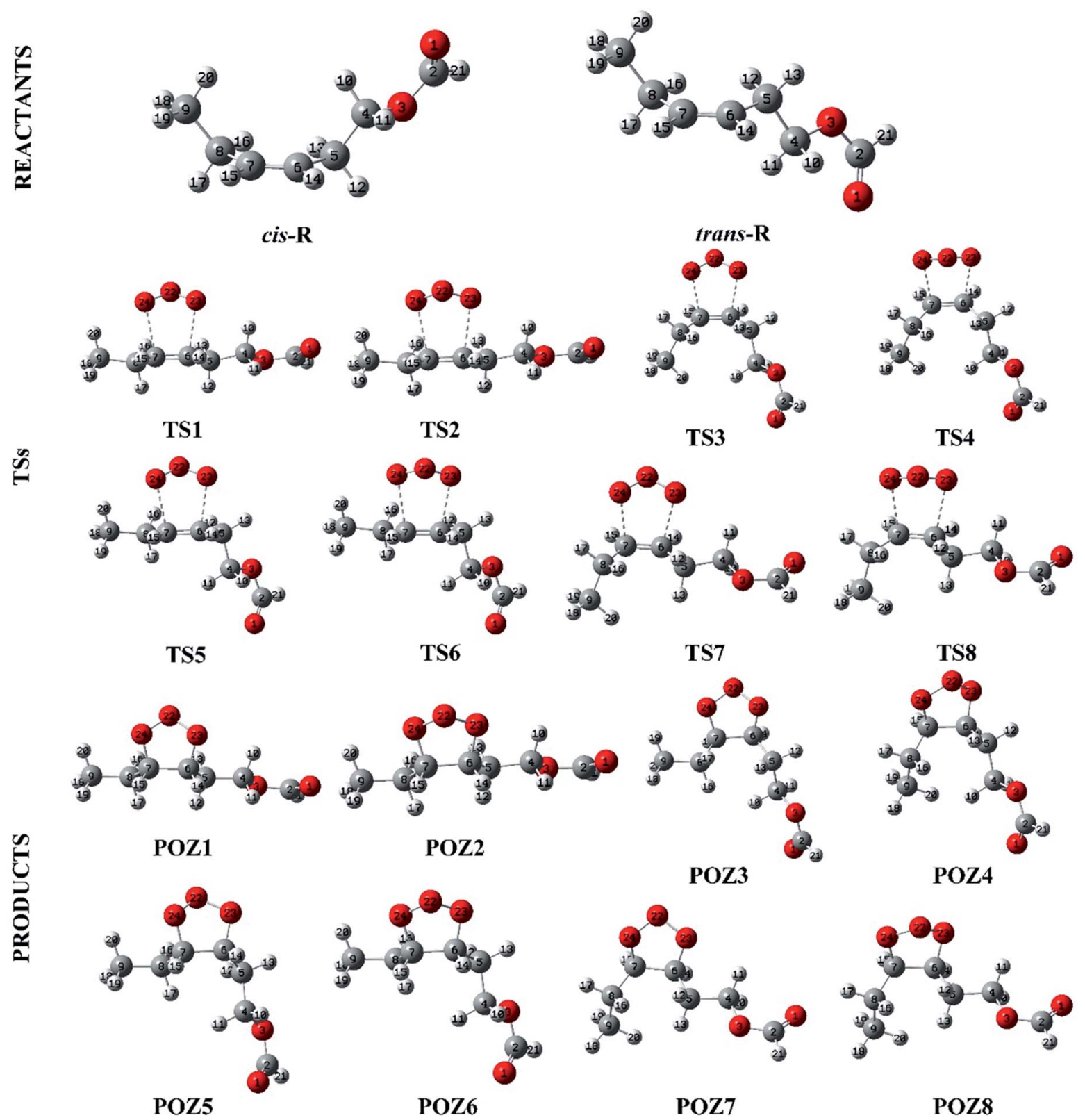

Fig. 4 Structures for the reactants, transition states and products along the cis-3-hexenyl formate $+\mathrm{O}_{3}$ reaction profile.

increased by more than 10 times, from $10^{-18} \mathrm{~cm}^{3}$ per molecule per s to $10^{-17} \mathrm{~cm}^{3}$ per molecule per s. Obviously, the farther the distance between the ester group and the $\mathrm{C}=\mathrm{C}$ bond, the smaller the influence of the ester group on the reactivity and the greater the reaction rate constants. For vinyl acetate, cis-2-hexenyl acetate (one $\mathrm{CH}_{2}$ group between the ester group and $\mathrm{C}=\mathrm{C}$ bond) and cis-3-hexenyl acetate (two $\mathrm{CH}_{2}$ groups between the ester group and $\mathrm{C}=\mathrm{C}$ bond), the rate constants increased from $3.0 \times 10^{-18} \mathrm{~cm}^{3}$ per molecule per s to $2.50 \times 10^{-17}$ and $5.77 \times$ $10^{-17} \mathrm{~cm}^{3}$ per molecule per s, respectively. For the cis-3-hexenyl compounds, the reactivity toward $\mathrm{O}_{3}$ also varies with the nature of the substituent. Table 1 compares the reactivity of cis-3-hexene, cis-3-hexen-1-ol (replacing $-\mathrm{CH}_{3}$ by $-\mathrm{CH}_{2} \mathrm{OH}$ ), cis-3-hexenyl formate (replacing $-\mathrm{CH}_{3}$ by $\left.-\mathrm{CH}_{2} \mathrm{OC}(\mathrm{O}) \mathrm{H}\right)$ and cis-3-hexenal (replacing $-\mathrm{CH}_{3}$ by $\left.-\mathrm{C}(\mathrm{O}) \mathrm{H}\right)$, with the rate constants at $14.4 \times$ $10^{-17}, 5.47 \times 10^{-17}, 4.06 \times 10^{-17}$ and $3.5 \times 10^{-17} \mathrm{~cm}^{3}$ per molecule per s, respectively, indicating the relative magnitude of electron-withdrawing effect of these substituents in the order $-\mathrm{C}(\mathrm{O}) \mathrm{H}>-\mathrm{CH}_{2} \mathrm{OC}(\mathrm{O}) \mathrm{H}>-\mathrm{CH}_{2} \mathrm{OH}$. The rate constants of cis-3hexenyl acetate, cis-3-hexenyl propionate and cis-3-hexenyl butyrate are all larger than that of cis-3-hexen-1-ol, which is the result that the alkyl group in ester group weakens the electron withdrawing effect of the ester group.

\section{Atmospheric implications}

The atmospheric implications of this work can be analyzed through comparison of the lifetimes of the cis-3-hexenyl esters with respect to reaction with the main atmospheric oxidants, 

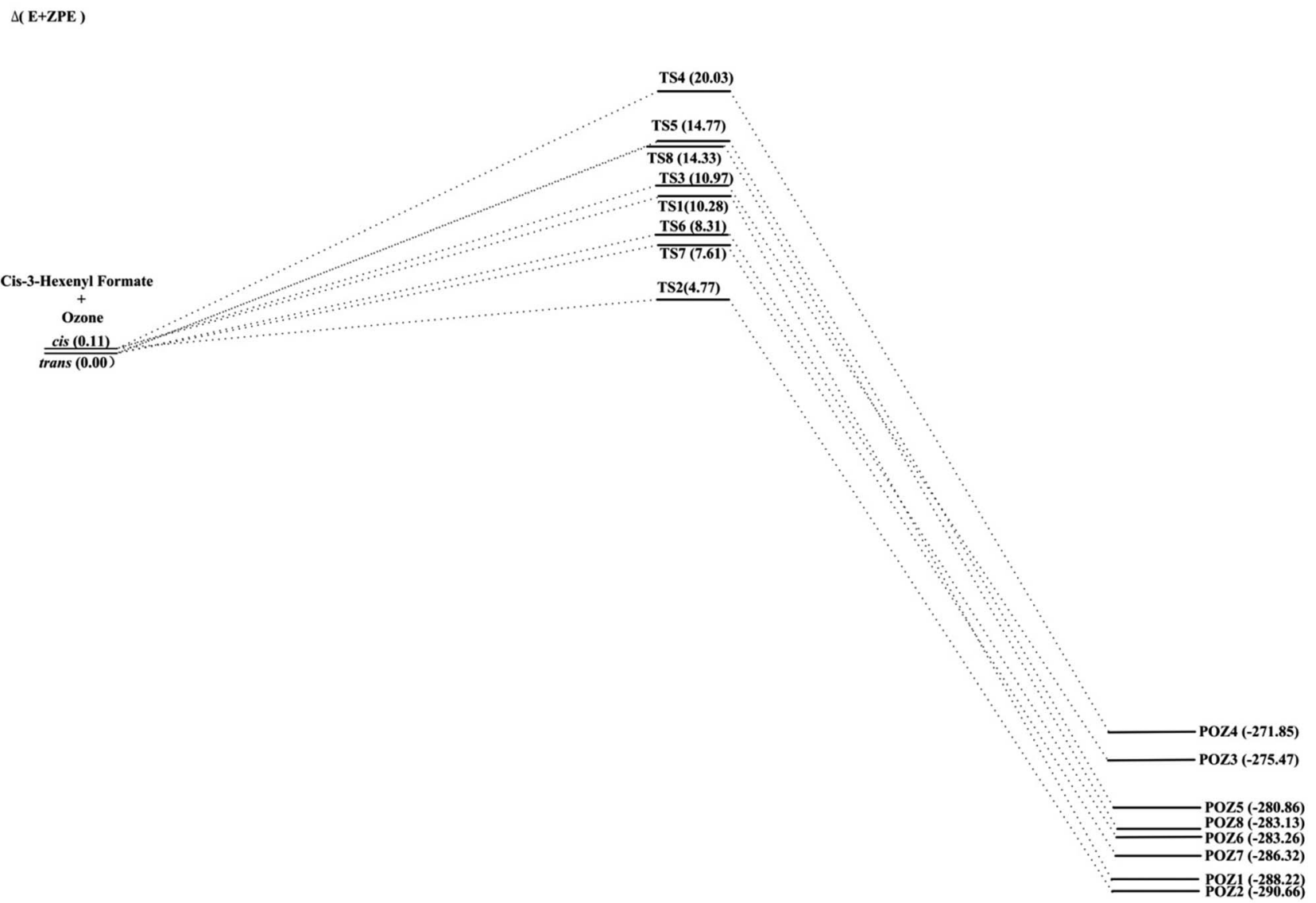

Fig. 5 BHandHLYP/6-311+G(d,p) energy profile (in $\mathrm{kJ} \mathrm{mol}^{-1}$ ) for the cis-3-hexenyl formate ozonolysis.

such as $\mathrm{OH}, \mathrm{NO}_{3}, \mathrm{O}_{3}$ and $\mathrm{Cl}$. Lifetimes were calculated using the expression $\tau=1 /(k[X])$, where $[X]$ represents the concentration of the oxidant and $k$ is the corresponding rate constant. Rate constants for these reactions are correlated with the highest occupied molecular orbital (HOMO) energies of the unsaturated VOCs. ${ }^{53,54}$ Thus, the rate constants without reported experimental values were estimated using their HOMO energies which were calculated at the $\mathrm{HF} / 6-31 \mathrm{G}^{* *}$ level of theory using the Gaussian 09 program and listed in Table S1. $\dagger$ The obtained rate constants for these cis-3-hexenyl esters and the calculated lifetimes are summarized in Table 2.

It is clear from Table 2 that reactions with $\mathrm{OH}, \mathrm{NO}_{3}$ radicals and $\mathrm{O}_{3}$ should all play important role in the atmospheric removal of the studied cis-3-hexenyl esters. Lifetimes estimated for these esters are all in the range of a few hours, which means that these esters are likely to be rapidly removed in the vicinity of their emission source. In the daytime, $\mathrm{OH}$ radical plays a major role; in the night, $\mathrm{NO}_{3}$ radical becomes the main

Table 1 Comparison of the rate constants $\left(\mathrm{cm}^{3}\right.$ per molecule per s) for reactions of $\mathrm{O}_{3}$ with a series of unsaturated esters at $298 \mathrm{~K}$ and atmospheric pressure

\begin{tabular}{|c|c|c|}
\hline Esters & Formula & $k_{\mathrm{O}_{3}}$ \\
\hline Vinyl acetate & $\mathrm{CH}=\mathrm{CH}_{2} \mathrm{OC}(\mathrm{O}) \mathrm{CH}_{3}$ & $3.0 \times 10^{-18}($ ref. 48$)$ \\
\hline Vinyl propionate & $\mathrm{CH}=\mathrm{CH}_{2} \mathrm{OC}(\mathrm{O}) \mathrm{CH}_{2} \mathrm{CH}_{3}$ & $5.3 \times 10^{-18}$ (ref. 49$)$ \\
\hline cis-3-Hexene & $\mathrm{CH}_{3} \mathrm{CH}_{2} \mathrm{CH}=\mathrm{CHCH}_{2} \mathrm{CH}_{3}$ & $14.4 \times 10^{-17}($ ref. 51$)$ \\
\hline cis-3-Hexen-1-ol & $\mathrm{CH}_{3} \mathrm{CH}_{2} \mathrm{CH}=\mathrm{CHCH}_{2} \mathrm{CH}_{2} \mathrm{OH}$ & $5.47 \times 10^{-17}($ ref. 24$)$ \\
\hline cis-3-Hexenal & $\mathrm{CH}_{3} \mathrm{CH}_{2} \mathrm{CH}=\mathrm{CHCH}_{2} \mathrm{CHO}$ & $3.5 \times 10^{-17}($ ref. 52$)$ \\
\hline cis-3-Hexenyl propionate & $\mathrm{CH}_{3} \mathrm{CH}_{2} \mathrm{CH}=\mathrm{CH}\left(\mathrm{CH}_{2}\right)_{2} \mathrm{OC}(\mathrm{O}) \mathrm{CH}_{2} \mathrm{CH}_{3}$ & $7.62 \times 10^{-17 a}$ \\
\hline cis-3-Hexenyl butyrate & $\mathrm{CH}_{3} \mathrm{CH}_{2} \mathrm{CH}=\mathrm{CH}\left(\mathrm{CH}_{2}\right)_{2} \mathrm{OC}(\mathrm{O})\left(\mathrm{CH}_{2}\right)_{2} \mathrm{CH}_{3}$ & $12.34 \times 10^{-17 a}$ \\
\hline
\end{tabular}

${ }^{a}$ This work. 
Table 2 Atmospheric lifetimes, $\tau$, for studied esters calculated using the corresponding rate constants

\begin{tabular}{|c|c|c|c|c|c|c|c|c|}
\hline Esters & \multicolumn{4}{|c|}{$k\left(\mathrm{~cm}^{3}\right.$ per molecule per $\left.\mathrm{s}\right)$} & \multicolumn{4}{|c|}{$\tau^{f}$ (hours) } \\
\hline cis-3-Hexenyl acetate & $7.84^{b}$ & 5.77 & 5.77 & $4.77^{e}$ & 3.5 & 9.6 & 6.9 & 116.5 \\
\hline cis-3-Hexenyl propionate & $4.07^{c}$ & 6.09 & 7.62 & $4.80^{e}$ & 6.8 & 9.1 & 5.2 & 115.7 \\
\hline cis-3-Hexenyl butyrate & $4.08^{c}$ & 6.25 & 12.34 & $4.82^{e}$ & 6.8 & 8.9 & 3.2 & 115.3 \\
\hline
\end{tabular}

oxidant for these esters; while ozone can compete with them either day or night. The contribution of $\mathrm{Cl}$ atoms seems small. However, due to their high reaction rate, it may be significant in areas with high chlorine atom concentrations, such as coastal areas and some mid-continental polluted areas. ${ }^{60-62}$ Other possible removal processes for these esters, such as photolysis, dry and wet depositions, could be considered negligible, since they do not absorb radiation in the actinic region, and are highly volatile and insoluble in water. ${ }^{63}$ It should be noted that the ozone concentration used in Table 2 is only the background concentration $(28 \mathrm{ppb})$ in the remote region, where $\mathrm{O}_{3}$ reactions have already been comparable to the reaction with $\mathrm{OH}$ and $\mathrm{NO}_{3}$ radicals. In some urban areas, ozone concentrations frequently exceed $120 \mathrm{ppb}$ and are even much higher. ${ }^{64,65}$ In this case, the reaction with ozone will become the most important degradation pathway of these unsaturated esters in the atmosphere.

Reactions of these unsaturated esters with ozone are expected to produce some carbonyl compounds (such as aldehydes, ketones or esters) and some organic nitrates, which could further be subject to reaction with $\mathrm{OH}$ or photolysis, contributing to the formation of secondary organic aerosol (SOA) or photochemical smog. Therefore, further studies should be conducted on the product distribution of these reactions and their contribution to the formation of SOA. In addition, for reactions with $\mathrm{OH}, \mathrm{NO}_{3}$ radicals and $\mathrm{Cl}$ atoms, both theoretical and experimental studies are still necessary to obtain their accurate rate constants and to reevaluate the atmospheric implications of these reactions.

\section{Conclusions}

In summary, the rate constants of the reactions of $\mathrm{O}_{3}$ with four cis-3-hexenyl esters and isoprene were measured using absolute method in a laminar flow reactor. At $298 \mathrm{~K}$ and atmosphere pressure, the following values (in $10^{-17} \mathrm{~cm}^{3}$ per molecule per $\mathrm{s}$ ) were obtained: $4.06 \pm 0.66$ for cis-3-hexenyl formate, $5.77 \pm 0.70$ for cis-3-hexenyl acetate, $7.62 \pm 0.88$ for cis-3-hexenyl propionate, $12.34 \pm 1.59$ for cis-3-hexenyl butyrate, and $1.23 \pm 0.16$ for isoprene. The results of isoprene and cis-3-hexenyl acetate showed very good agreement with the literature data, indicating the reliability of this reactor in the kinetic study. To the best of our knowledge, it was the first kinetic study for the $\mathrm{O}_{3}$ reactions with cis-3-hexenyl formate, cis-3-hexenyl propionate and cis-3- hexenyl butyrate. Theoretical calculations were also performed to better understand the kinetics and the mechanism of the title reactions. The results showed that reactions of these unsaturated esters with $\mathrm{O}_{3}$ are slower than their corresponding parent alkene because of the electron-withdrawing effect of the-OC(O) $\mathrm{R}$ function group, and the extent of this effect was obviously dependent on the structure of the R group, as well as the relative distance between the double bond and the ester group. It can be found from the calculation of atmospheric lifetimes that reaction with $\mathrm{O}_{3}$ is one of the most important removal pathways for these esters in the atmosphere. They are expected to have short atmospheric lifetimes due to their high reactivity with $\mathrm{OH}, \mathrm{NO}_{3}$ radicals and $\mathrm{O}_{3}$. Therefore, further research on the reaction products will be necessary to assess the effect of these reactions on regional pollution.

\section{Conflicts of interest}

There are no conflicts to declare.

\section{Acknowledgements}

This work was supported by the National Natural Science Foundation of China (No. 91544228, 41575125, 41605102, 41775125), the National Key Research and Development Program of China (2016YFC0202205), and the Presidential Foundation of Hefei Institutes of Physical Science (No. YZJJ201508), CAS.

\section{Notes and references}

1 A. Guenther, C. N. Hewitt, D. Erickson, R. Fall, C. Geron, T. Graedel, P. Harley, L. Klinger, M. Lerdau, W. A. Mckay, T. Pierce, B. Scholes, R. Steinbrecher, R. Tallamraju, J. Taylor and P. Zimmerman, J. Geophys. Res., 1995, 100, 8873-8892.

2 A. H. Goldstein and I. E. Galbally, Environ. Sci. Technol., 2007, 41, 1514-1521.

3 J. D. Fuentes, M. Lerdau, R. Atkinson, D. Baldocchi, J. W. Bottenheim, P. Ciccioli, B. Lamb, C. Geron, L. Gu, A. Guenther, T. D. Sharkey and W. Stockwell, Bull. Am. Meteorol. Soc., 2000, 81, 1537-1575.

4 R. Atkinson and J. Arey, Atmos. Environ., 2003, 37, S197-S219. 
5 E. G. Colman, M. B. Blanco, I. Barnes and M. A. Teruel, $R S C$ Adv., 2015, 5, 30500-30506.

6 A. Hofzumahaus, F. Rohrer, K. D. Lu, B. Bohn, T. Brauers, C. C. Chang, H. Fuchs, F. Holland, K. Kita, Y. Kondo, X. Li, S. R. Lou, M. Shao, L. M. Zeng, A. Wahner and Y. H. Zhang, Science, 2009, 324, 1702-1704.

7 L. K. Whalley, D. Stone, B. Bandy, R. Dunmore, J. F. Hamilton, J. Hopkins, J. D. Lee, A. C. Lewis and D. E. Heard, Atmos. Chem. Phys., 2016, 16, 2109-2122.

8 X. R. Ren, D. van Duin, M. Cazorla, S. Chen, J. Q. Mao, L. Zhang, W. H. Brune, J. H. Flynn, N. Grossberg, B. L. Lefer, B. Rappengluck, K. W. Wong, C. Tsai, J. Stutz, J. E. Dibb, B. T. Jobson, W. T. Luke and P. Kelley, J. Geophys. Res.: Atmos., 2013, 118, 5770-5780.

9 Lipids in Plant and Algae Development. Subcellular Biochemistry, ed. Y. Nakamura and Y. Li-Beisson, Springer, Cham, 2016, vol. 86, pp. 427-443.

10 M. M. Maja, A. Kasurinen, T. Holopainen, R. Julkunen-Tiitto and J. K. Holopainen, Sci. Total Environ., 2016, 547, 39-47.

11 J. Arey, A. M. Winer, R. Atkinson, S. M. Aschmann, W. D. Long and C. L. Morrison, Atmos. Environ., Part A, 1991, 25, 1063-1075.

12 G. Konig, M. Brunda, H. Puxbaum, C. N. Hewitt, S. C. Duckham and J. Rudolph, Atmos. Environ., 1995, 29, 861-874.

13 F. Brilli, T. M. Ruuskanen, R. Schnitzhofer, M. Müller, M. Breitenlechner, V. Bittner, G. Wohlfahrt, F. Loreto and A. Hansel, PLoS One, 2011, 6, e20419.

14 K. Jardine, G. A. Barron-Gafford, J. P. Norman, L. Abrell, R. K. Monson, K. T. Meyers, M. Pavao-Zuckerman, K. Dontsova, E. Kleist, C. Werner and T. E. Huxman, Photosynth. Res., 2012, 113, 321-333.

15 W. Kirstine, I. Galbally, Y. R. Ye and M. Hooper, J. Geophys. Res., 1998, 103, 10605-10619.

16 F. Brilli, L. Hortnagl, I. Bamberger, R. Schnitzhofer, T. M. Ruuskanen, A. Hansel, F. Loreto and G. Wohlfahrt, Environ. Sci. Technol., 2012, 46, 3859-3865.

17 W. E. Chehab, R. Kaspi, T. A. Savchenko and K. Dehesh, Proceedings of ANAS, Biological Sciences, 2010, 65, 145-151.

18 D. Helmig, L. F. Klinger, A. Guenther, L. Vierling, C. Geron and P. Zimmerman, Chemosphere, 1999, 38, 2163-2187.

19 J. Ruther, J. Chromatogr. A, 2000, 890, 313-319.

20 M. M. Maja, A. Kasurinen, T. Holopainen, S. KontunenSoppela, E. Oksanen and J. K. Holopainen, Tree Physiol., 2015, 35, 975-986.

21 R. Atkinson, J. Arey, S. M. Aschmann, S. B. Corchnoy and Y. H. Shu, Int. J. Chem. Kinet., 1995, 27, 941-955.

22 E. Grosjean and D. Grosjean, Int. J. Chem. Kinet., 1998, 30, 21-29.

23 Y. B. Gai, M. F. Ge and W. G. Wang, Atmos. Environ., 2011, 45, 53-59.

24 X. X. Lin, Q. Ma, C. Q. Yang, X. F. Tang, W. X. Zhao, C. J. Hu, X. J. Gu, B. Fang, Y. B. Gai and W. J. Zhang, RSC Adv., 2016, 6, 83573-83580.

25 C. Gonzalez and H. B. Schlegel, J. Phys. Chem., 1990, 94, 5523-5527.
26 M. J. Frisch, G. W. Trucks, H. B. Schlegel, G. E. Scuseria, M. A. Robb, J. R. Cheeseman, G. Scalmani, V. Barone, B. Mennucci, G. A. Petersson, H. Nakatsuji, M. Caricato, X. Li, H. P. Hratchian, A. F. Izmaylov, J. Bloino, G. Zheng, J. L. Sonnenberg, M. Hada, M. Ehara, K. Toyota, R. Fukuda, J. Hasegawa, M. Ishida, T. Nakajima, Y. Honda, O. Kitao, H. Nakai, T. Vreven, J. A. Montgomery Jr, J. E. Peralta, F. Ogliaro, M. Bearpark, J. J. Heyd, E. Brothers, K. N. Kudin, V. N. Staroverov, R. Kobayashi, J. Normand, K. Raghavachari, A. Rendell, J. C. Burant, S. S. Iyengar, J. Tomasi, M. Cossi, N. Rega, J. M. Millam, M. Klene, J. E. Knox, J. B. Cross, V. Bakken, C. Adamo, J. Jaramillo, R. Gomperts, R. E. Stratmann, O. Yazyev, A. J. Austin, R. Cammi, C. Pomelli, J. W. Ochterski, R. L. Martin, K. Morokuma, V. G. Zakrzewski, G. A. Voth, P. Salvador, J. J. Dannenberg, S. Dapprich, A. D. Daniels, Ö. Farkas, J. B. Foresman, J. V. Ortiz, J. Cioslowski, and D. J. Fox, Gaussian 09, Revision A.02, Gaussian, Inc., Wallingford CT, 2009.

27 K. H. Møller, R. V. Otkjær, N. Hyttinen, T. Kurtén and H. G. Kjaergaard, J. Phys. Chem. A, 2016, 120, 10072-10087. 28 D. Johnson and G. Marston, Chem. Soc. Rev., 2008, 37, 699716.

29 S. M. Aschmann, J. Arey and R. Atkinson, Atmos. Environ., 2002, 36, 4347-4355.

30 T. L. Malkin, A. Goddard, D. E. Heard and P. W. Seakins, Atmos. Chem. Phys., 2010, 10, 1441-1459.

31 R. Atkinson, D. L. Baulch, R. A. Cox, J. N. Crowley, R. F. Hampson, R. G. Hynes, M. E. Jenkin, M. J. Rossi and J. Troe, Atmos. Chem. Phys., 2006, 6, 3625-4055.

32 IUPAC, Task Group on Atmospheric Chemical Kinetic Data Evaluation-Data sheets for gas phase organic reactions: $\mathrm{O}_{x}$ + VOC, http://iupac.pole-ether.fr/.

33 F. Kaufman, J. Phys. Chem., 1984, 88, 4909-4917.

34 L. F. Keyser, J. Phys. Chem., 1984, 88, 4750-4758.

35 H. Chen, Y. Ren, M. Cazaunau, V. Daële, Y. Hu, J. Chen and A. Mellouki, Chem. Phys. Lett., 2015, 621, 71-77.

36 W. J. Massmana, Atmos. Environ., 1998, 32, 1111-1127.

37 L. Vereecken and J. S. Francisco, Chem. Soc. Rev., 2012, 41, 6259-6293.

38 E. Gaona-Colman, M. B. Blanco, I. Barnes, P. Wiesen and M. A. Teruel, RSC Adv., 2017, 7, 2733-2744.

39 W. H. Miller, Y. Zhao, M. Ceotto and S. Yang, J. Chem. Phys., 2003, 119, 1329.

40 C. Aieta, F. Gabas and M. Ceotto, J. Phys. Chem. A, 2016, 120, 4853-4862.

41 C. Aieta and M. Ceotto, J. Chem. Phys., 2017, 146, 214115.

42 C. Eckart, Phys. Rev., 1930, 35, 1303-1309.

43 W. T. Duncan, R. L. Bell and T. N. Truong, J. Comput. Chem., 1998, 19, 1039-1052.

44 B. Long, W. J. Zhang, X. F. Tan, Z. W. Long, Y. B. Wang and D. S. Ren, J. Phys. Chem. A, 2011, 115, 1350-1357.

45 B. Long, X. F. Tan, C. R. Chang, W. X. Zhao, Z. W. Long, D. S. Ren and W. J. Zhang, J. Phys. Chem. A, 2013, 117, 5106-5116.

46 J. R. Alvarez-Idaboy, N. Mora-Diez and A. Vivier-Bunge, J. Am. Chem. Soc., 2000, 122, 3715-3720. 
47 J. R. Alvarez-Idaboy, N. Mora-Diez, R. J. Boyd and A. VivierBunge, J. Am. Chem. Soc., 2001, 123, 2018-2024.

48 B. Picquet-Varrault, M. Scarfogliero and J. F. Doussin, Environ. Sci. Technol., 2010, 44, 4615-4621.

49 E. Gaona Colman, M. B. Blanco, I. Barnes and M. Teruel, Chem. Phys. Lett., 2013, 579, 11-15.

50 J. Li, Y. H. Sun, H. J. Cao, D. D. Han and M. X. He, Struct. Chem., 2014, 25, 71-83.

51 E. Grosjean and D. Grosjean, Int. J. Chem. Kinet., 1996, 28, 461-466.

52 J. H. Xing, M. Ono, A. Kuroda, K. Obi, K. Sato and T. Imamura, J. Phys. Chem. A, 2012, 116, 8523-8529.

53 M. D. King, C. E. Canosa-Mas and R. P. Wayne, Phys. Chem. Chem. Phys., 1999, 1, 2231-2238.

54 Q. K. Timerghazin and P. A. Ariya, Phys. Chem. Chem. Phys., 2001, 3, 3981-3986.

55 D. Rodriguez, A. Rodriguez, I. Bravo, A. Garzon, A. Aranda, Y. Diaz-de-Mera and A. Notario, Int. J. Environ. Sci. Technol., 2015, 12, 2881-2890.

56 J. A. Logan, J. Geophys. Res., 1985, 90, 10463-10482.

57 W. J. Bloss, M. J. Evans, J. D. Lee, R. Sommariva, D. E. Heard and M. J. Pilling, Faraday Discuss., 2005, 130, 425-436.
58 Y. Shu and R. Atkinson, J. Geophys. Res., 1995, 100, 72757281.

59 A. A. P. Pszenny, W. C. Keene, D. J. Jacob, S. Fan, J. R. Maben, M. P. Zetwo, M. Springer-Young and J. N. Galloway, Geophys. Res. Lett., 1993, 20, 699-702.

60 A. Rodriguez, I. Bravo, D. Rodriguez, M. Tajuelo, Y. Diaz-deMera and A. Aranda, RSC Adv., 2016, 6, 21833-21843.

61 J. A. Thornton, J. P. Kercher, T. P. Riedel, N. L. Wagner, J. Cozic, J. S. Holloway, W. P. Dube, G. M. Wolfe, P. K. Quinn, A. M. Middlebrook, B. Alexander and S. S. Brown, Nature, 2010, 464, 271-274.

62 X. X. Liu, H. Qu, L. G. Huey, Y. H. Wang, S. Sjostedt, L. M. Zeng, K. D. Lu, Y. S. Wu, M. Hu, M. Shao, T. Zhu and Y. H. Zhang, Environ. Sci. Technol., 2017, 51, 9588-9595.

63 M. B. Blanco, I. Bejan, I. Barnes, P. Wielsen and M. A. Teruel, J. Phys. Chem. A, 2009, 113, 5958-5965.

64 Y. Wang, P. Konopka, Y. Liu, H. Chen, R. Muller, F. Ploger, M. Riese, Z. Cai and D. Lu, Atmos. Chem. Phys., 2012, 12, 8389-8399.

65 X. Pu, T. J. Wang, X. Huang, D. Melas, P. Zanis, D. K. Papanastasiou and A. Poupkou, Sci. Total Environ., 2017, 603-604, 807-816. 